\title{
E-Learning \& Education: A Case Study of the Use of the You Tube in Teaching Skills- Integration
}

\author{
Abdullah Khuwaileh \\ Jordan University of Science \& Technology \\ Tariq Khwaileh \\ Qatar University
}

\begin{abstract}
The central aim of this paper is to investigate whether the internet accessories like the You Tube can really help in improving the process of teaching English in TESOL settings.This is because we all know that the use of the internet has considerable potential for encouraging learning and teaching with a fun factor away from classical andtraditional teaching. Definitely, we investigate the effect of the You Tube on the speaking and skills-integration. To serve the purpose of this paper, we established two research groups: a control group where traditional teaching was employed and an experimental group where fresh You Tubes clips were employed. The TESOL learners in both groups were then subjected to oral presentations and tests which were compared and contrasted to investigate any significant statistical difference. The tabulation of results revealed that the experimental group where the You Tube clips were used performed better than the control group, developed confidence, used idiomatic English and proper pronunciation, became more fluent and culturally aware. Moreover, the experimental group showed open mindedness of how to use English effectively and managed to make skill-integration which in turn created a classroom language centred approach where the teacher's role was minimized, and the TESOL learner's role was maximized. Our study is concluded with a number of research and practical recommendations related to the use of the You Tube in learning English at home without going to any academic institution as the You Tube enters our houses everyday.
\end{abstract}

Keywords: E-learning Applied Linguistics Skills-IntegrationTESOL

\section{Introduction}

In recent years, integration of instructional technology (IT) into the universities and schools classrooms has become a significant part of education to the extent that IT has been incorporated into the teaching curricula or syllabi to facilitate the process of learning styles. The purpose of this study is to demonstrate how the You Tube can be used to teach speaking through skill integration and how it solves the problems of the individual differences in TESOL intermediate classes. In fact, this is a problem which is encountered in any TESOL classroom. We all know that every FL/SL class in some way is multilevels in terms of language skills and competence. In a certain class, we might find some students who can read and write better than their classmates. Simultaneously, we can find other students who are better at speaking or listening. Some students have a good grammatical rules background but they are unable to speak. Experience has revealed that some TESOL learners do not speak in the class but they surprise their classmates in written exams as they get higher grades in exams than their colleagues who usually speak and participate.

In Jordan where this study was conducted, all our students were school leavers having recently undertaken the Jordanian General Secondary Certificate Examination and studied two years in the Department of English. All the data, examples, frameworks of discussions were taken from our own ESL situation at Jordan University of Science and Technology (hereafter JUST). English is the medium of instruction at this university which in turn makes it very difficult to avoid individual differences because differences can be obviously noticed in learning second and foreign languages. All the major skills: reading, writing, listening and speaking are equally needed by these students. Nevertheless, the skill of speaking has not been given the right emphasis in our syllabuses. The negligence of speaking in our situation is due to a number of reasons. First, compared with the other major skills, we found it difficult to write ESL speaking materials to train students in oral communication. Experience has revealed that importing TESOL speaking books or material could not be always appropriate to be taught in the Arab World due to the cultural differences. For example, concept on alcohol, boyfriends, girlfriends, etc. are not suitable for our students who belong to the Arab and Islamic culture which is conservative. Second, some students and even teachers (in our situation) think that to teaching speaking is unmanageable and could be a waste of time because speaking practice should be with native speakers of English who are not employed in our universities in general. 
When speaking is taught, the individual differences hinder the process of learning because only a limited number of EF/SL learners participate and speak voluntarily. The other students feel shy to speak in English because they do not want their spoken English to be monitered and scrutinized by their classmates. Because of these beliefs, we decided to carry out our investigation which brought about useful results in this respect as we will see in the following sections.

\section{Literature Remarks}

So many methodologists and theorists argue that teaching is not only an educational discipline, but it is an art which requires instructional technology in the classroom (e.g., Newby 2000). While much of the literature written on TESOL in general and on ELT in particular has focused on the skills of reading and writing and sometimes on listening, a number of ELT practitioners and thinkers voiced their worries over the negligence of speaking. Reviewing a number of ELT course books, one notices the negligence of speaking in ESP and ELT in general, and in EST in particular. For example, the Widdowson series (1979) Reading and Thinking in English focuses on the other skills (e.g., reading, writing, etc.) and ignores speaking. Bates/Dudley-Evans (1976) Nucleus: General Science emphasizes grammatical structures and reading required in EST and ignores speaking. Adkins/McKean (1983) Text to Note concentrates mainly on listening and ignores speaking. Chaplen (1981) and many other course books do the same.

Although speaking activities in TESOL have been relatively ignored, a number of needs analyses in different TESOL situations have proved its importance and necessity in these situations. Moreover, some ESP thinkers and practitioners believe that speaking is crucial in TESOL, ELT and ESP. Thus, Robinson (1991) argues:

"If not a need, speaking is often a want, since in many students'opinions oral proficiency is the best indicator of mastering alanguage." (Robinson 1991: 105).

In addition, James (1988: 112) argues that in TESOL or ESP, it is the speaking that is the "make or break" skill for students. Approximately the same point is also expressed by McKenna (1987: 25-28). Ellis (2003: 2-9) echoes the same point about speaking and simultaneously proposes the use of the task approach as a practical and enjoyable method. Supporting the task approach in teaching speaking is Richard and Rodgers (2001:233-35) who argues that the task types needs to be applied and investigated:

\section{Distinguishing different task types is important, as it allows researchers to investigate which types most effectively promote learning.}

It follows from the discussion above that speaking is not only a major required skill, but also a want that is put high on the list of the wants of the students involved in ELT. Although this is the case that all ELT students need and require speaking and in this respect they are similar, they are different in their performance because of the individual differences among them. McKay and Tom (2005: 2-3) argue that:

\section{Adult ELT learners are in most cases heterogeneous in terms of their linguistic proficiency, background \\ knowledge, expectation, learning styles, confidence, motivation and personal circumstances.}

Nunan (1992) echoes the same concept of individual differences. As early as in1981, Krashen expressed his viewpoint about SL individual differences. He also refers not only to the many variations among learners, but also to those of contexts and interaction levels where language occurs. As mentioned above, it seems also that the application of tasks in the classroom is worth applying as recommended by Ellis (2003: 2-9) and Richard and Rodgers (2001: 233-35).

\section{Methodology}

At this stage, it is worth mentioning that we took our samples from the students studying English in the Department of EnglishLanguage and Linguistics in the JUST. In the first semester of the Academic year 2017-18, the researcher was entitled to teach two sections of the course Oral Skills numbered as 213 which means the course is intended for second year students studying for the B.A in English Language. The two section/groups (25 students in each) were homogeneous in the sense that they had a similar background in English (intermediate). Nevertheless, they were heterogeneous in their performance when it comes to classroom activities and to tests. Because they were admitted to the JUST, they were all subjected to the university admission rules. This entails a seventy five grade and above in the GSEC (General Secondary Education Certificate). In order to improve their speaking skills and reduce the students' individual differences which are common and expected problems in any TESOL situation, we decided to exploit the status of teaching the two groups of the same course. The two groups which included males and females aged from nineteen to twenty one years have a very strong motivation towards their English studies. 
The first group (A) was the experimental group and the second group ( B) was the control group. With the control group, the teacher followed the traditional methods of teaching speaking activities where all the students were given one activity with one input and one performance with one output. With the experimental group (group A), the researcher used You Tube clips and adapted the methods of teaching speaking where we adjusted our teaching to concentrate on three or more outputs for the same speaking activities, skills, sub-skills, etc. that are believed to influence the students' individual differences which in turn affect their ability in speaking and oral presentations. That is to say, we put much emphasis on the oral speaking inputs/activities (You Tube clip) that would generate several outputs to satisfy all the levels of students. The adjustment of our teaching extended over twelve weeks. In weeks fourteen and fifteen, both groups were tested in speaking.

In short, our experiment was based on devising several (8 inputs) activities that would have one input but required many outputs to serve all the levels of students. Some of those outputs required were ranging from simple to middle and difficult outputs to serve all the academic levels of students. The simple required outputs were intended for the poor students, the middle outputs were intended for the average students and the most difficult ones were intended for the excellent students. The following inputs are samples from the 8 inputs/activities we employed:

\section{Activity 1:}

(Input): On the data show, all the students (25) of the experimental group were shown a You Tube clip of a car accident of about 2 minutes. The required outputs were:

a. A group of students must describe what happened in the clip

b. Another group must reach a decision on who was the wrong driver

c. The last group is supposed to describe what should have been done to avoid the car accident including the nature of streets and infra-structure where the accident occurred, the car and the driver.

It is clear that output (a) is intended for the poor students because it is a matter of repeating what was seen. Nothing new was required of them. However, output (b) is more difficult than (a) because the average group must decide who caused the accident. They need to argue a little bit to reach a decision which entails more practice. As group (c) is supposed to study all the conditions and geography surrounding the accident area, they need to be deeper in their thoughts than the other two groups. For example , they need to use the unreal condition grammar (e.g., type three of the if-clauses) because they would be speaking about something which is based on imagination. This task requires also knowledge about the traffic system and driving rules. In short, the last task is the most demanding task which is devised for the excellent students. In this case, the three groups are given one input (the clip as mentioned above), but they were required to perform three different types of activities with three different outputs or levels of difficulty.

\section{Activity 2}

(Input): All the 25 students listen to a report about the recent economic recession worldwide in terms of its nature, causes and latest consequences. The required outputs were:

a. About a third of the students (the poor ones) will be required to paraphrase the economic problem which they listened to.

b. Another group of students (average ones) will be required to find out other causes of that economic problem apart from those mentioned in the listening passage.

c. The last group (the excellent ones) need to give presentations on the expected solutions and the outlook of that problem.

Obviously, the last required output is the most difficult one because the students need to think deeply and predict what would happen in future and what solutions should be proposed to solve that problem. Nevertheless, the first input does not require any deep thought as doing the task is a matter of repeating what they heard using their own words. In other words, it is a matter of paraphrasing. In short, all the class levels will be served each in accordance with his points of strength.

Over 12 weeks, we continue to use tasks similar to those mentioned above. Where it was possible, we used to switch on informal discussion about each activity to have feedback about the classroom performance. Then, we tested both groups (the experimental group and the control group) to check the effect of the multi-level tasks on the final performance of the experimental group. Latter, descriptive and inferential statistics were employed. Descriptive statistics (averages, numbers and percentages) were used to reflect compare and contrast the performance of both groups (A \& B). The inferential statistical chi-square test was also applied on the data to check the significance level of our findings. We chose the Chi-square test to process statistically the students' grades, percentages and averages. In such data based on frequencies and numbers, that test is the appropriate one, as recommended by statisticians. 


\section{Discussion}

As stated above, the central aim of this paper is to solve the problem of multi-level classes which include learners' individual differences. Therefore, the differences among the grades of the learners including their reasons and interpretation will guide our discussion. The four tables below represent the performance of the control group and the experimental one beforeandafter setting our experiment to gauge the effect of the new methods of teaching applied in the classroom of the experimental group.

To start with, Table 1 and table 2 show the performance of the experimental including their different averages. While the 25 students of the experimental group generated an average of only 13.2 before the research experiment, the students' performance average reached 17.9 after conducting the experiment. This difference seems to have been achieved by the successful methods of teaching represented by the activities we devised to encourage all the students to find something to talk about and each in accordance with his/her academic level and linguistic ability. This process encouraged poor students to talk and simultaneously feel that they were creative in their talk though their task was just to repeat what they saw in the video clip. In other words, the output required of them was simple to meet their needs. Therefore, from our point of view, their output required of them was based on paraphrasing or repeating what they saw in the video clip. Such an output is simple, but from the poor students' point of view, that output was an achievement as they expressed that in our informal discussions with after each class. The simplicity of their outputs developed gradually the poor students' confidence while speaking to audience. For example, the question of "describing what they saw" was simple because the students were required talk in English only about what they saw. In other words, describing what they saw was something mechanical; no creativity was required.

At the same time, the excellent students were really creative because they were challenged by the kind of outputs they were required to achieve. The questions: "How can we avoid car accidents or how can we avoid traffic jams in rush hours?" were challenging because their answers have confused governments everywhere, not only students. In other words, solving these traffic problems is not easy. This implies that what is suggested by the students should be very thoughtful, challenging and creative. Therefore, the excellent students analyzed the problems and solutions dramatically like addressing the role of the three important elements (car, driver and road, etc.). In fact their traffic recommendations were very interesting to the extent that they did not only improve their spoken language, but also their etiquettes of arguing, interruption and disagreeing. For example, at the beginning they used to interrupt in an uncivilized way by talking without being authorized to talk. Later, they used to interrupt after they use the T-shaped body language.

Table 1. The grades of the 25 students' pre-test who were in the experimentalgroup. Total on. 25 . Total average of performance is $\mathbf{1 3 . 2}$

\begin{tabular}{|l|l|l|}
\hline $\begin{array}{l}\text { No. } \\
\text { students }\end{array}$ & $\begin{array}{l}\text { Grades out of } \\
30 \%\end{array}$ & Average \\
\hline 5 & 55678 & 6.2 \\
\hline 6 & 9991010 & 7.8 \\
\hline 9 & 1414151515 & \\
16161617 & 15.3 \\
\hline 5 & $\begin{array}{l}2222232525 \\
2\end{array}$ & 23.8 \\
\hline
\end{tabular}

This is also shown by having one speaker at a time. At the beginning of experiment conduction, the students of the experimental group used to speak in a very random manner which was untidy and messy. Later, after a couple of weeks, they started to be very tidy and well-organized in their classroom discussion. It is worth noting that their traffic notes and recommendations were transferred to the Department of Civil Engineering which appreciated their practical suggestions and found them practical and useful.

Table 2. The grades of the 25 students' post-test who were in the experimentalgroup. Total no. 25. Total average of performance is $\mathbf{1 7 . 9}$

\begin{tabular}{|l|l|l|}
\hline No. of students & Grades out of 30\% & Average \\
\hline 2 & 1011 & 10.5 \\
\hline 3 & 131314 & 13.3 \\
\hline 4 & 15151616 & 15.5 \\
\hline 4 & 17171818 & 17.5 \\
\hline 5 & 1919202121 & 20 \\
\hline 4 & 22222324 & 22.5 \\
\hline 3 & 262728 & 27 \\
\hline
\end{tabular}


The usefulness of our activities is confirmed also by the difference in the averages of performance. While the average was only 23.8 before we conduct our teaching experiment, it reached 27 after conducting the experiment. Supporting the finding of the difference in averages of the experimental group is the finding of the average of the control group. We might easily notice that the average of the control group performance was 23 (table 3 ) at the beginning of the semester which is similar to that of the experimental group before conducting the experiment. Nevertheless, the difference has become evident after conducting the experiment (i.e., at the end of the semester). While the average of the control group was only 25 (table 3), it reached 27 in the case of the experimental group (table 2). These statistical variations reveal that the effect of the teaching experiment (multi-levels tasks) had a great effect on the students' performance of the experimental group.

It is worth noting that we used two open tasks with our students. The open task is the task which might talked about from different corners and different perspectives. The open task might generate endless discussions. The first open task we used was maps showing borders, geography, geology (e.g., mountains, hills, etc), cities, zigzagging lines, etc. They found this task both interesting and engaging as we noticed that the task included a wide range of ideas ranging from simple ideas to difficult and analytical ideas. Considering the classroom channels of information, we noticed that the following ideas or questions were found very simple and therefore the poor students enjoyed doing them:

- Describing the borders of a certain country on the map,

- Explaining the meanings of colours used in map,

- Listing the most interesting cities and/or places.

These questions were stimulating and encouraging for poor students or below average students. This was shown by the number of classroom participants who volunteered to answer such questions. The students seemed very confident and sure about their answers.

On the other hand, the following ideas or questions were found challenging to excellent students:

- Measuring distance between cities and/or places,

- Predicting what is below the surface of the earth on the map

by analyzing the colours used and their degree of darkness,

- Predicting through measuring the square area or the cubic size of a certain place, mountain, lake, etc.

From the student participation we found that these questions and/or activities were very challenging to the excellent students. However, they enjoyed them because they were engaged in multi levels activities. For example, they needed to do some oral arithmetical operations, some measurementswere done by means of rulers, others did written calculations, some agreements and disagreements and finally they needed to present their conclusions to answer our questions. Not only excellent students were engaged in doing these difficult tasks, but also poor students benefited from the discussion of the excellent ones to the extent that they sneaked into the discussion in a shy manner. That is to say, they started to interfere in the discussion talking only about the simple side of the open task. For example, while the excellent students did the difficult arithmetical operations, the poor ones offered to note down the resulting numbers or calculations.

Table 3 The grades of the 25 students' pre-test who were in the controlgroup. Total on. 25 . Total average of performance is $\mathbf{1 3 . 2}$

\begin{tabular}{|c|c|c|}
\hline $\begin{array}{ll}\begin{array}{l}\text { No. } \\
\text { students }\end{array} & \text { of } \\
\end{array}$ & $\begin{array}{l}\text { Grades out of } \\
30 \%\end{array}$ & Average \\
\hline 4 & 4556 & 5 \\
\hline 7 & $\begin{array}{llllll}8 & 8 & 7 & 10 & 9 & 8 \\
7 & & & & & \end{array}$ & 8.1 \\
\hline 9 & $\begin{array}{llll}12 & 14 & 13 & 14 \\
15 & 16 & 15 & 16 \\
17 & & & \end{array}$ & 14.6 \\
\hline 5 & $\begin{array}{llll}21 & 22 & 23 & 24 \\
25 & & & \\
\end{array}$ & 23 \\
\hline
\end{tabular}


Table 4. The grades of the 25 students' post-test who were in the controlgroup. Total no. 25 . Total average of performance is 17.9

\begin{tabular}{|l|l|l|}
\hline No. of students & Grades out of 30\% & Average \\
\hline 3 & 899 & 8.6 \\
\hline 1 & 12 & 12 \\
\hline 5 & 1313131414 & 13.4 \\
\hline 5 & 1717171818 & 17.4 \\
\hline 4 & 20202021 & 20.2 \\
\hline 4 & 22222323 & 22.5 \\
\hline 3 & 252525 & 25 \\
\hline
\end{tabular}

Because of the limitation of space and time, we will not continue discussing the performance of the experimental group. In stead, we will focus on the advantageous aspects of multi-levels activities. The first aspect is the kind of activities the students enjoyed more. In fact, as mentioned in the methodology section above, 8 multi-levels activities or inputs were used in the experimental classroom. Those were: car accident, economic recession, companies in terms of structure and function, transportation, maps, cost of marriage, disadvantages of the internet and the role of woman in different societies. It is obvious that all those topics were chosen carefully because they were argumentative on the one hand, and most intermediate students seemed to have the linguistic competence to talk orally about them on the other hand. Being argumentative topics,they encouraged the students to talk about them warmly and with great enthusiasm. Moreover, the topics are not technical and therefore the students seemed to have the required grammatical structure and vocabulary they needed to talk about the topics.

Obviously, all the eight inputs/activities employed in the experimental classroom were well-received by the students, enjoyable and interesting. Nevertheless, some of those were more stimulating and steamy than others. Actually, most of the experimental group students enjoyed remarkably talking about four topics which were car accident, cost of marriage, the internet and the role of woman in different societies. When employing these inputs, we noticed that the students were very keen to talk about those topics to the extent that even poor students were so and used language interference and code switching to express themselves. From the students' body language including their facial expressions, we noticed that the students did not even like the idea of stopping the discussion about the cost of marriage. A plausible explanation for this is that the topic of marriage and the cost of it is a very hot topic in Jordan in particular, and in the Arab World in general. So many young people willing to marry have expressed their concern about the lack of money for getting married.

On the other hand, car accidents are the concern of all people in Jordan because everyday people hear and read about fatal car accidents in different mass media. The students were very keen to talk about this topic probably because they are highly educated about this topic whichis heavily covered in mass media, as mentioned above. The theory of being educated about these topics are applicable also on the topics of the internet and the role of woman in the Jordanian society. In fact, these topics were carefully chosen by the researcher as they touch any student in the classroom and therefore no reading is needed to be able to talk about.

We also found that the result came logical and reasonable as the figure below shows. The figure reveals that most poor

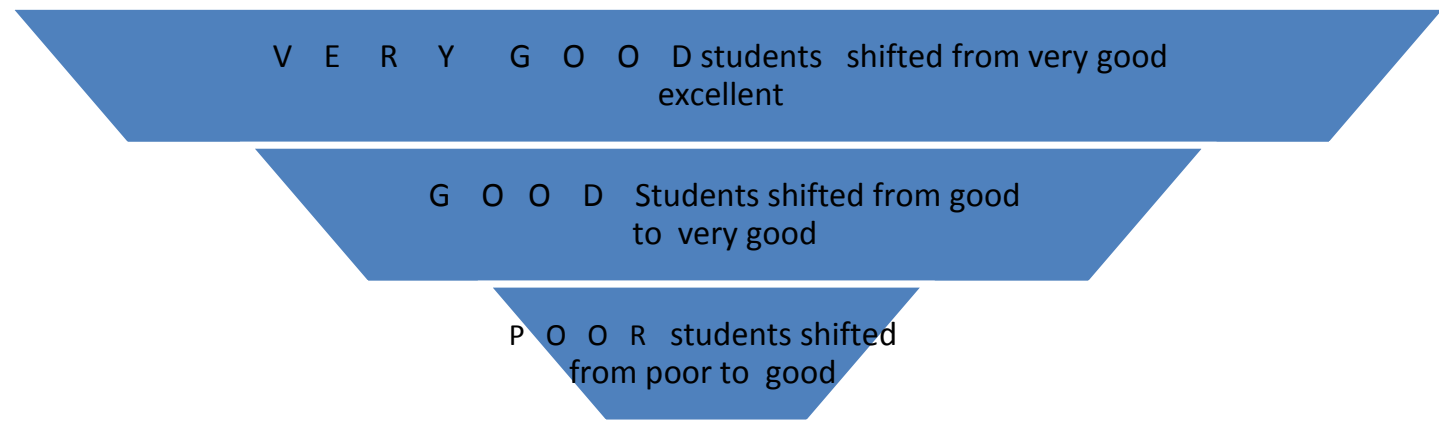

Students developed their speaking ability to become good. And the good ones developed their ability to become very good. Finally, the very good ones developed their ability to become excellent.

\section{Conclusion}

Although our experiment took about 14 weeks to carry out in the classroom of the experimental group, our approach does show significant results as we successfully manage to develop the students' ability and confidence in Aural and 
oral skills including discussion, conversation, spoken interruption, asking and answering questions. Their gradual progress was remarkable when we relate it to the control group performance as we saw above.

Moreover, our findings reveal that the students of the experimental group found themselves in a situation where skill integration was applied automatically. All the skills of Listening, speaking, writing and reading were needed to process the inputs and talk about the outputs. The students were instructed to watch a video clip where listening was needed and simultaneously, they took notes where writing was used. Later on, they read their notes and spoke about them.

We have also found that the results were reasonable in showing the progress of the students' performance. The poor students' level of performance was improved to reach a good level, and the good students' level was developed to reach the very good one and finally the very good one's has become excellent, as mentioned above. This means that all the students of the experimental group benefitted from the inputs of the experiment we used. These findings encourage other researchers to apply the same experiment in other ESP/ESL/EFL/TESOL context where they might investigate the effect of the experiment on writing, for instance. Others might investigate its effect on grammar. But the most important implication for the classroom teachers would be the right choice of the inputs to be used as they should not be contaminated with any cultural element that may create problems for the learners. Highly sensitive topics like politics and religion were avoided in our case as these topics might be dangerous in the Middle East.

\section{Notes:}

1. The course 213 is a compulsory course for all the students of English. It is described Eng. (213) Aural-Oral Skills : 3 Credit hours, Prerequisite Eng. 113:

The course aims at developing the students' ability in conversation by discussing various topic of general and specific nature concentrating on the organization and development of ideas. Students are encouraged to speak and discuss matters using different techniques of interaction, such as group work and dialogue. Students are expected to be interactively involved and are assumed to acquire strategies needed for effective communication.

2. All the topics to talk about were carefully chosen to meet the criteria of being well known by the students, being hot topic, being important for all the learners and beingsensitive.

3. We would like to thank the statisticians of the Department of Applied Mathematics,Jordan University of Science and Technology, for their statistical help in processing our data.

\section{References}

Bates, M. and Dudley-Evans, T. (1976) Nucleus: General Science.London: Longman.

Ellis, R. (2003) Task-based Language Learning and Teaching. Oxford:Oxford University Press.

Krashen, S. (1981) Second language acquisition and second Language Learning.Oxford: pergamon.

Newby, T. (2000) Instructional Technology for Teaching and learning.New Jersey:Prentice Hall.

Nunan, D. (1992) Designing Task for the Communicative Classroom. Cambridge:CUP.

Richard, J. and Rodgers, T. (2001) Approaches and Methods in Language Teaching.Cambridge: Cambridge University Press,

Robinson, P. (1991) ESP Today: A practitioner's Guide. Hemel Hempstead: Prentice Hall.

Widdowson, H. G. (1979) Reading and Thinking in English: Exploring Function. Oxford: OUP.

Widdowson, H. G. (1979) Learning Purpose and Language Use. Oxford: OUP. 